Original Article

\title{
EVALUATION OF WOUND HEALING ACTIVITY OF POLYHERBAL FORMULATION
}

\author{
MADHURI A. THENG, G. R. SITAPHALE, K. R. BIYANI
}

Department of Pharmacology, Anuradha College of Pharmacy, Chikhli, Pin 443201, MS-Mharastra, India Sant Gadge Baba Amravati University, Amravati

Email: thengmadhuri7@gmail.com

Received: 20 Aug 2017, Revised and Accepted: 13 Oct 2017

\section{ABSTRACT}

Objective: The present study describes the anti-microbial activity of Acacia arabica and Butea monosperma bark extract.

Methods: For this purpose aqueous extract of bark were prepared by "Soxhlet extraction method". The experimentally induced burn wound model in rats by "Excision method".

Results: As a result of this study it was found that the extract of bark generally revealed antimicrobial and wound healing activity.

Conclusion: The result of the study suggest that the Acacia arabica and Butea monosperma bark of polyherbal gel effective in accelerating wound healing process.

Keywords: Acacia arabica, Butea monosperma, Wound Healing, Excision method, Soxhlet extraction, Polyherbal Formulation

(C) 2017 The Authors. Published by Innovare Academic Sciences Pvt Ltd. This is an open access article under the CC BY license (http://creativecommons.org/licenses/by/4.0/] DOI: http://dx.doi.org/10.22159/ijcpr.2017v9i6.23420

\section{INTRODUCTION}

In India, medicines based on herbal origin have been the basis of treatment and cure for various diseases. Moreover, Indian folk medicine comprises numerous prescriptions for therapeutic purposes such as healing of wounds, inflammation, skin infections, leprosy, diarrhoea, scabies, venereal disease, ulcers, snake bite. More than $80 \%$ of the world's population still depends upon traditional medicines for various skin diseases. Herbal medicines in wound management involve disinfection, debridement and providing a moist environment to encourage the establishment of the suitable environment for the natural healing process. A large number of plants are used by folklore traditions in India for treatment of cuts, wounds and burns. The drugs selected for this work were Acacia arabica and Butea monosperma. These two important herbs are reported to have significant antibacterial, immunomodulatory and anti-inflammatory activities which are complementary to wound healing process. The growing popularity of natural and herbal medications, easy availability of raw materials, cost-effectiveness and the paucity of reported adverse reaction, prompted us to formulate a polyherbal topical preparation and assess its wound healing ability. The combination is used in order to enhance the wound healing activity.

\section{MATERIALS AND METHODS}

\section{Materials}

The plants were selected on the basis of their antimicrobial activities and their medicinal uses reported in the literature. The herbs (Acacia arabica and Butea monosperma) were purchased from the local area of city and authenticated by Taxonomist in the department of Botany, Shri Shivaji Science and Arts College, Chikhli.
All other chemicals were of analytical grade and used without further purification.

\section{Preparation of extract}

The powdered of Acacia arabica bark and Butea monosperma bark were used for extraction. The powder is extracted in soxhlet apparatus with ethanol. The extraction procedure were carried out till a sufficient quantity of extract was obtained. The solvent was removed by distillation method.

Formulation of topical gel

The United State Pharmacopeia (USP) defines gels as semisolid, being either suspensions of small inorganic particles or large organic molecules interpenetrated with liquid. In the first case, the organic particles, such as bentonites, from a three-dimensional "house of card" structure throughout the gel. This is a true two-phase system, as the inorganic particles are not soluble but merely dispersed through the continuous phase [1]. Gels formulations of different concentration using different base were formulated the various ingredients used for the formulations. By using the above ingredients three different formulations were prepared. All formulations were having Carbopol gel base. Formulations I, II, were $1 \%$ of each concentration of extract and formulation III was $2 \%$ concentration (i.e. $1 \%$ of each extract).

The concentration of extract of plant Acacia arabica, Butea monosperma were used on trial and error basis and studying its activity. Finally these three formulations were selected and prepared. The evaluations of all three formulations were made and pharmacological wound healing activity of all formulations were studied.

The formulae of prepared herbal gel formulations incorporating the herbal drugs extract is given below.

Table 1: Formulation of topical gel

\begin{tabular}{llll}
\hline Name of Ingredient & Formulation I & Formulation II & Formulation III \\
\hline Carbopol 940 & $1 \mathrm{gm}$ & $1 \mathrm{gm}$ & $1 \mathrm{gm}$ \\
Glycerin & $5 \mathrm{ml}$ & $5 \mathrm{ml}$ & $5 \mathrm{ml}$ \\
Tri-ethanolamine & q. s. & q. s. & q. s. \\
Propyl paraben & q.s. & q. s. & q.s. \\
Acacia arabica & $1 \mathrm{gm}$ & $-\mathrm{gm}$ & $1 \mathrm{gm}$ \\
Butea Monosperma & ---- & $100 \mathrm{ml}$ & $1 \mathrm{gm}$ \\
Distilled water q. s. & $100 \mathrm{ml}$ & $100 \mathrm{ml}$ \\
\hline
\end{tabular}




\section{Wound healing studies}

A partial thickness burn wound model was employed as per [2]. The rats will be anaesthetized with diethyl ether and the hair on the back will be shaved with a sterile blade. The shaved area was disinfected with $70 \%(\mathrm{v} / \mathrm{v})$ ethanol. Then burn wound will be created by pouring hot molten wax $(2 \mathrm{gm})$ at $\left(80^{\circ} \mathrm{C}\right)$. The wax circular opening. The wax will be allowed to remain on the skin till it gets solidified. Immediately after injury and on subsequent days, all the gel will be daily applied topically for $21 \mathrm{~d}$ or till complete epitheliazation which ever will earlier. After animal recovered completely from anesthesia, they were kept in individual cages and followed all norms of good laboratory practice in carrying the animals [3]. The animals were randomly divided into 5 groups and each group containing 6 animals. The treatments of each gel $(500 \mathrm{mg} /$ rats $)$ were applied topically once a day [4].

Group I: Control group.

Group II: Test group treated with Acacia Arabica gel. (Formulation I)

Group III: Test group treated with Butea monosperma gel. (Formulation II)

Group IV: Test group treated with (Polyherbal gel) (Formulation III)

Group V: (Reference Standard Marketed Preparation). Wound contraction will be monitored by measuring the progressive changes in row wound area, plan metrically on the transparent paper, from which the wound surface area will be evaluated. The tracing was then transferred to $1 \mathrm{~mm}^{2}$ graph sheet, from which the wound surface area was evaluated. The evaluated surface area was then employed to calculate the percentage of wound contraction, taking the initial size of the wound, $300 \mathrm{~mm}^{2}$, as $100 \%$ by using the following equation.

Wound Contraction $(\%)=$ $\underline{\text { Initial Wound Size - Specific day Wound Size }} \times$

$$
\text { Initial Wound Size } \quad \times 100
$$

\section{Statistical analysis}

Experimental data are expressed as mean \pm (SEM) standard error of mean. Statistical analysis was performed by using one way ANOVA followed by Dunnet test.

\section{RESULTS AND DISCUSSION}

The prepared herbal gel formulations incorporating herbal extracts i.e. Acacia Arabica and Butea monosperma extract are subjected for the in vitro evaluation and stability studies by using various parameters.

\section{Wound contraction}

Wound contraction is another parameter used to assess wound healing. Significant wound contraction was shown in table.

Table 2: Evaluation of wound healing activity

\begin{tabular}{llllll}
\hline \multirow{2}{*}{ Gr. No. } & Formulation & \multicolumn{4}{l}{ Area of wound during different days of observation (\%) } \\
\cline { 3 - 6 } & & $\mathbf{4}$ & $\mathbf{8}$ & $\mathbf{1 2}$ & $\mathbf{1 6}$ \\
\hline 1 & Control & $8.31 \pm 0.7160$ & $8.48 \pm 0.8152$ & $8.44 \pm 0.7819$ & $8.39 \pm 0.8852$ \\
2 & Formulation I & $10.88 \pm 0.4042$ & $24.22 \pm 0.4350$ & $36.13 \pm 0.7087$ & $67.88 \pm 0.5417$ \\
3 & Formulation II & $7.72 \pm 0.7821$ & $18.16 \pm 0.5232$ & $48.58 \pm 0.5512$ & $70.20 \pm 0.5510$ \\
4 & Formulation III & $9.88 \pm 0.8595$ & $28.36 \pm 0.9520$ & $51.16 \pm 0.6677$ & $85.52 \pm 0.3358$ \\
5 & Reference Standard & $12.89 \pm 0.7487$ & $29.38 \pm 0.7275$ & $53.95 \pm 0.6425$ & $75.55 \pm 0.6432$ \\
\hline
\end{tabular}

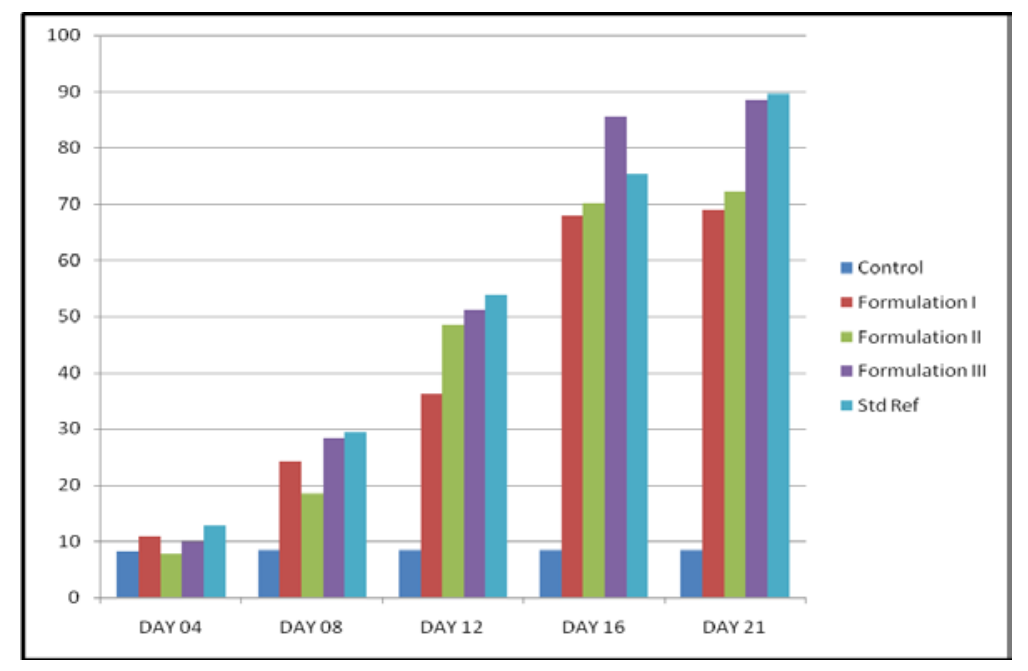

Fig. 1: Evaluation of wound healing activity

\section{DISCUSSION}

From the above remarks, it can be concluded that all the parameters of the selected herbs were within in the Pharmacopoeial limit indicates the high-quality quality of raw materials. The extract studies showed the presence of selected active constituents in significant amount. The microbiological studies indicated that the formulations possess anti-microbial activity against tested organisms. The wound contraction studies revealed that the wound contraction increases on increasing the concentration of herbal extract. The study also reveal that the better activity of polyherbal formulation may be due to the synergistic action of the plants constituents present in the formulation. Thus, the prepared topical gels possess a versatile approach in healing the wound contraction.

\section{CONCLUSION}

In pharmacological evaluation, Acacia arabica showed significant wound healing effect as compared to control group, Butea monosperma showed significant wound healing effects as compared control group. The polyherbal gel that is the combination of these two drugs showed synergistic wound healing activity as compared to all herbal drugs individual activity. The prepared herbal gel showed significant wound healing activity and the combination of 
Acacia arabica, Butea monosperma had synergistic wound healing activity. In present study it is concluded that wound healing potential of polyherbal gel is better than individual gel i.e. Acacia arabica, Butea monosperma gel. In polyherbal gel there is the higher percentage of wound contraction. The present study is a platform and the work would go on a long a way in extracting the potential of Acacia arabica, Butea monosperma gel for the various activity.

\section{ACKNOWLEDGEMENT}

We are grateful to our principal Dr. K. R. Biyani, Guide Prof. G. R. Sitaphale, Mr. M. A. Deshmukh, staff members, Director and Our honorable chairman Shri. R. S. Bondre for providing us necessary facilities to carry out the research project.

\section{CONFLICT OF INTERESTS}

Declared none

\section{REFERENCES}

1. Lacman Leon, Herbert A Leberman. Theory and practice of Industerial Pharmacy; Nirali publication. Third edition; 1987. p. 557.

2. Barua CC, Talukdar A, Barua AG, Sarma RK, Bora RS. Evaluation of the wound healing activity of methanolic extract of Azadirachta Indica (Neem) and Tinospora cordifolia (Guduchi) in rats. Pharmaclogy Res Online 2010;1:70-7.

3. Future. Journal of Pharmaceutical; 2002. p. 160-3.

4. Jason KO, MD Joel, D Herbert. The effect of ZD6474, an inhibitors of VEGF signaling; On cutaneous wound healing in mice. J Surgical Res 2005;129:251-2.
5. K Mohan AV. Effect of topical phenytoin on burn wound healing in rats. Indian J Exp Biol 2011;49:56-9.

6. Ahmad NS, Mohd SA, Ahmad A. Effect of carica papaya linn, latex on the healing of burns wounds in rats. J Sains Kesihatan Malaysia 2005;3:39-47.

7. Moon RS, Shrikhande R, Purohit N. Formulation and study of burn wound effect of herbal creams advance in Pharmacology and Toxicology. Indian J Pharm Sci 2007;8:1-25.

8. Gopalkrishnan V, Rao Longanathan, VK Sharma, V Bhavna. Antimicrobial activity of extract of acalyphaindica linn. Indian J Pharm Sci 2000;62:347-9.

9. K Ramanjaneyulu, A Bhargavi, P Rajvarma. Evaluation of phytochemical and antibacterial activity of Butea monosperma leaf extract. Int J Pharm Res 2011;2:1563-5.

10. Rajvaidhya Sourbh, GK Signh. A review on Acacia arabica in Indian medicinal plants. Int J Pharm Sci Res 2012;3:1995-2005.

11. Subalakshmi M, Saranya A, Maheswari MU, Jarina A, Kavimani S. An overview of the current methodologies used for the evaluation of drugs having wound healing activity. Int J Exp Pharmacol 2014;4:127-31.

12. Kumar A. Wound healing and ficus arnottiana Miq. Indian Health J 2011;5;68-58.

13. Manas Kumar Das, Pariya Mazumder. Evaluation of antibacterial activity in Butea monosperma: a comprehensive review. Int Res J Plant Sci 2011;2;7;215-9.

14. Sapna Malviya. Medicinal attributes of Acacia arabica linn a comprehensive review on ethophamacological claims. Int J Pharm Life Sci 2011;4:830-7.

15. Aly Usama F. Preparation and evaluation of novel topical gel preparation for wound healing in diabetics. Int J Pharm Pharm Sci 2012;4:76-8. 